\title{
The multistep process of vaginal cancer arising from deep infiltrating endometriosis: a case report
}

Jee Hyun Kim', Seung Hun Song ${ }^{2 *}$, Gwangil Kim³, Kyoung Ah Kim and Woo Ram Kim

\begin{abstract}
Background: Malignant transformation of endometriosis in extraovarian sites remains rare. Furthermore, the process is not definitely understood.

Case presentation: Herein, we report the case of a 40-year-old premenopausal nulligravida woman who presented with vaginal bleeding and who was finally diagnosed with a vaginal cancer originating from endometriosis and with a synchronous endometrial cancer. A gynecologic examination revealed a multiple polypoid mass on the posterior vaginal fornix. Magnetic Resonance Imaging of the pelvis showed two masses abutting respectively on the anterior uterine wall, and in the rectovaginal septum. The patient underwent a total laparoscopic excision of the rectovaginal mass, radical hysterectomy and low anterior resection of the rectum. The lesions were diagnosed as endometriosis, endometriosis-associated complex hyperplasia and endometrioid cancer. Furthermore, a synchronous endometrioid endometrial cancer was reported.
\end{abstract}

Conclusions: This case revealed the multistep process of malignant transformation of deep infiltrating endometriosis. The progression was individualized between implantation sites and in the same organ.

Keywords: Deep infiltrating endometriosis, Vaginal cancer originating from endometriosis, Synchronous endometrial cancer, Endometriosis-associated complex hyperplasia, Endometriosis-associated endometrioid cancer

\section{Background}

Endometriosis is defined as the abnormal presence of endometrial tissue, most often on the ovaries, fallopian tubes, around the ureters, and more rarely in extrapelvic locations, such as bowel, rectum, and bladder [1-3]. It can rarely be presenting as vaginal mass and vaginal endometriosis is difficult to diagnosis $[4,5]$. Endometriosis is considered a gynecological benign condition. However, malignant transformation of endometriosis occurs in less than $1 \%$ of endometriosis cases, and $78.7 \%$

\footnotetext{
*Correspondence: shsong@chamc.co.kr

2 Department of Comprehensive Gynecologic Cancer Center,

CHA Bundang Medical Center, CHA University School of Medicine,

Seongnam-si, Gyeonggi-do 13496, South Korea

Full list of author information is available at the end of the article
}

of them had ovarian endometriosis transforming into clear cell or endometrioid ovarian cancer [6]. Recently, the malignant process of abdominal wall endometriosis which was transformed to clear cell borderline tumor has been reported [7], while malignant transformation of deep infiltrating endometriosis has been rarely reported [8], however, the malignant process is not yet well understood.

Endometriosis is associated with the risk of endometrial cancer $[9,10]$. Since the hormonal milieu may influence the pathogenesis of these two diseases, women with endometriosis have an increased risk of subsequent endometrial cancer [11]. When endometriosis-associated cancer and endometrial cancer coexist, the differential diagnosis to determine whether these diseases are double 
primary cancers or metastatic cancer from each can be challenging.

Herein, we report the case of a 40-year-old woman diagnosed with vaginal cancer originating from endometriosis and synchronous endometrial cancer.

\section{Case presentation}

A 40-year-old premenopausal nulligravida woman presented with vaginal bleeding in January 2020. The patient was otherwise well, had no prior surgery, and was not taking hormone medication. Her medical history was significant for morbid obesity, with a body mass index (BMI) of $36.4 \mathrm{~kg} / \mathrm{m}^{2}$.

A gynecologic examination revealed a multiple polypoid mass on the posterior vaginal fornix. (Fig. 1). Punch biopsy revealed endometriosis. The cervix appeared normal. A cervical smear showed reactive cellular changes but was negative for human papilloma virus. Magnetic Resonance Imaging of the pelvis showed two masses abutting respectively on the anterior uterine wall, and in the rectovaginal septum. (Fig. 2), diffuse thickening of endometrium without gross mass, and a $4.4 \mathrm{~cm}$ mass in the left ovary. A sigmoidoscopy detected an invasive polypoid lesion protruding into the rectum and biopsy revealed endometriosis (Fig. 3). She decided to undergo a surgery to remove lesions and confirm the pathologic diagnosis.

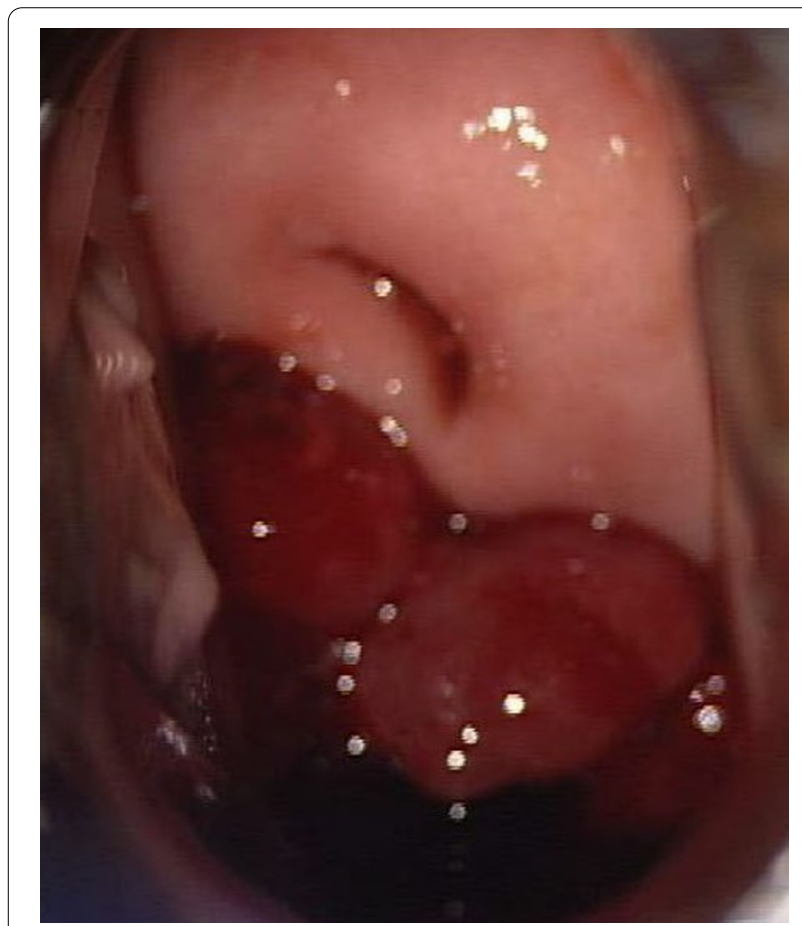

Fig. 1 Multiple polypoid masses on the posterior vaginal fornix

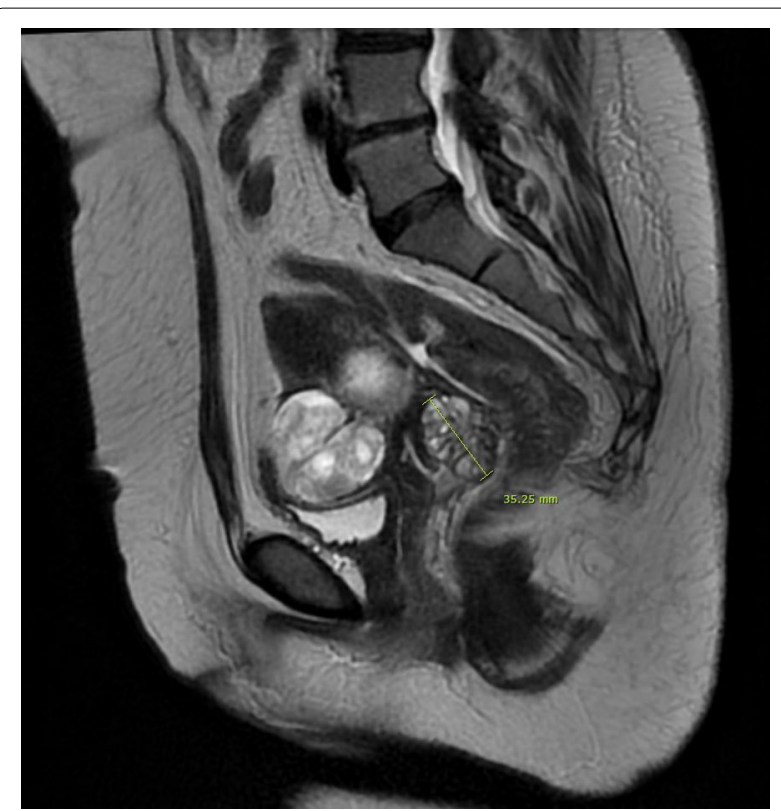

Fig. 2 Magnetic Resonance Imaging of the pelvis finding of a rectovaginal mass which invades vaginal and rectal wall

Firstly, the vaginal protruding mass was excised completely. Secondly, the globular mass were adequately removed via laparoscopy. Thirdly, dilatation and curettage of endometrial tissue was performed. Laparoscopic findings showed $5 \times 4 \times 4$ and $4 \times 3 \times 3 \mathrm{~cm}$ globular mass on the anterior uterine wall (Fig. 4) and a $3 \times 3 \times 2 \mathrm{~cm}$ globular mass on the rectovaginal septum; all of which were filled with chocolate-colored fluid and cheezy like materials. Histopathologically, the vaginal polypoid

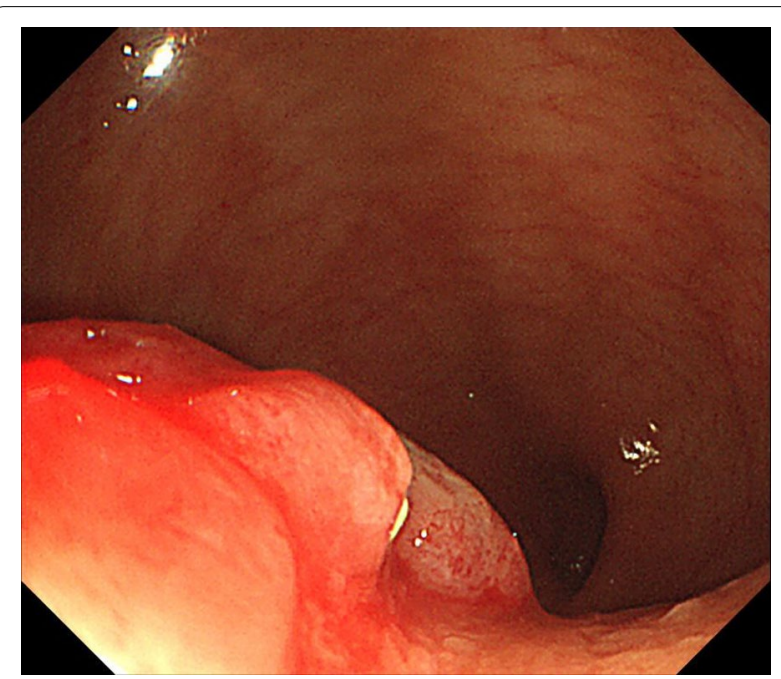

Fig. 3 Sigmoidoscopic finding of rectal endometriosis 


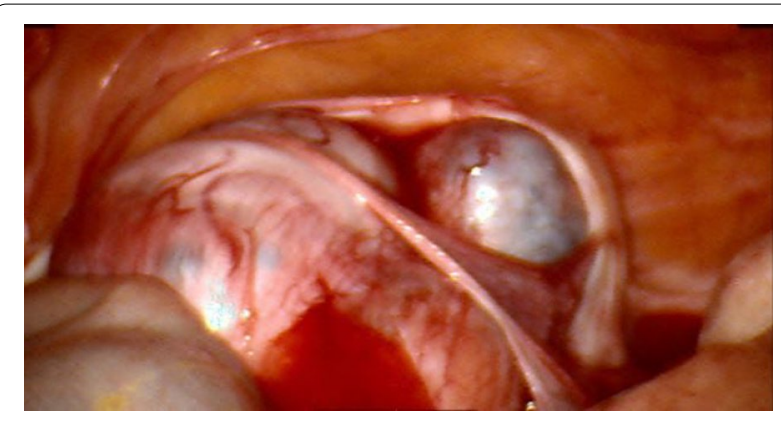

Fig. 4 Intraoperative finding of globular lesions on the anterior uterine wal

mass was diagnosed as endometriosis-associated complex hyperplasia and endometrioid cancer, International Federation of Gynecologic Oncology (FIGO) grade I/III. Meanwhile, globular lesions on anterior uterine wall and rectovaginal mass was diagnosed as endometriosis-associated complex hyperplasia. Furthermore, a synchronous endometrioid endometrial cancer, FIGO grade II/III was reported.

After being confirmed as a case of synchronous vaginal and endometrial cancer, a staging surgery for endometrial cancer and en bloc extirpation of the remnant rectovaginal mass were performed. The patient underwent a total laparoscopic excision of the rectovaginal mass, radical hysterectomy and low anterior resection of the rectum. The remnant rectovaginal mass was diagnosed as only endometriosis, which invaded extensively to the rectal mucosa. Perineural invasion in the specimen of the vagina was absent. The lack of perineural invasion did not request a subsequent lymph nodal dissection [12]. The resection margin of parametria, vaginal vault, and rectum were invaded by endometriosis but, free of cancer. Finally, the patient was diagnosed as endometriosisassociated endometrioid vaginal cancer and synchronous endometrioid endometrial cancer (stage 1A1) (Fig. 5). One month post operation, she was treated with dienogest and was clinically free of disease (no evidence of disease recurrence in the imaging study) for 8 months since undergoing last surgery.

\section{Discussion and conclusions}

Vaginal cancer constitutes $1-2 \%$ of all gynecologic malignancies. The most common histological subtype is squamous cell carcinoma, and the established risk factors include HPV infection, smoking, and decreased immune function [13]. The second most common subtype is adenocarcinoma, accounting for $15 \%$ of all primary vaginal cancer [14]. Most adenocarcinoma cases correlate with benign endometriosis [15]. In a recent comprehensive review, 37 histologically documented cases of primary vaginal cancer emerged from endometriosis [16]. In the review, 25 tumors were of epithelial histology (17 endometrioid carcinoma; 3 clear cell carcinoma; and 5 adenocarcinoma not otherwise specified), whereas 12 tumors were of sarcomatous histology.

Sampson first established the specific criteria for defining a cancer arising from endometriosis [17]: (1) the presence of benign endometrial tissue and cancer in the same site, (2) the presence of endometrial stroma surrounding the glands, and (3) the exclusion of metastasis from another primary site. According to these criteria, the vaginal mass was diagnosed as vaginal endometrioid carcinoma associated with endometriosis.

In the vaginal mass, complex hyperplasia presented synchronously with endometrioid cancer in the background of endometriosis. The step-by-step transformation process, from typical endometriosis, to atypical endometrioma, and finally to cancer, is well documented in endometriosis-associated ovarian cancer [18]. The case reveals the transition process from benign endometriosis to complex hyperplasia to endometrioid cancer in deep infiltrating endometriosis. Atypical endometriosis is considered a histologically as intermediate features between benign and malignant [19]. This term corresponds to architecturally complex and cytologically atypical proliferative lesions that resemble atypical hyperplasia arising in the endometrium. This sequential change of deep infiltrating endometriosis to malignancy has not been reported.

In this case study, rectovaginal endometriosis might have invaded the vaginal and rectal wall with a polypoid protruding appearance [20]. The main mass, located in the rectovaginal septum and cul-de-sac transformed to complex hyperplasia, whereas vaginal endometriosis transformed into endometrioid carcinoma. Meanwhile, rectal endometriosis did not develop into hyperplasia nor carcinoma. The case showed the difference in the degree of malignant change according to the organ where endometriosis is implanted; the finding was not found in the literature.

Hyperestrogenism is associated with the malignant transformation of endometriosis, and the microenvironment provided by endometriosis facilitates excess estrogen accumulation through several mechanisms [21]. Normally, aromatase is absent in a eutopic endometrial tissue, but in an endometriotic tissue, it is present in high levels [22]. This enzyme catalyzes the conversion of androstenedione and testosterone into estrone and estradiol, respectively. Its presence in endometriotic tissue leads to the constitutive expression of estradiol, and excess estradiol can result in cellular proliferation by inducing cytokine production [23]. In addition, estradiol 


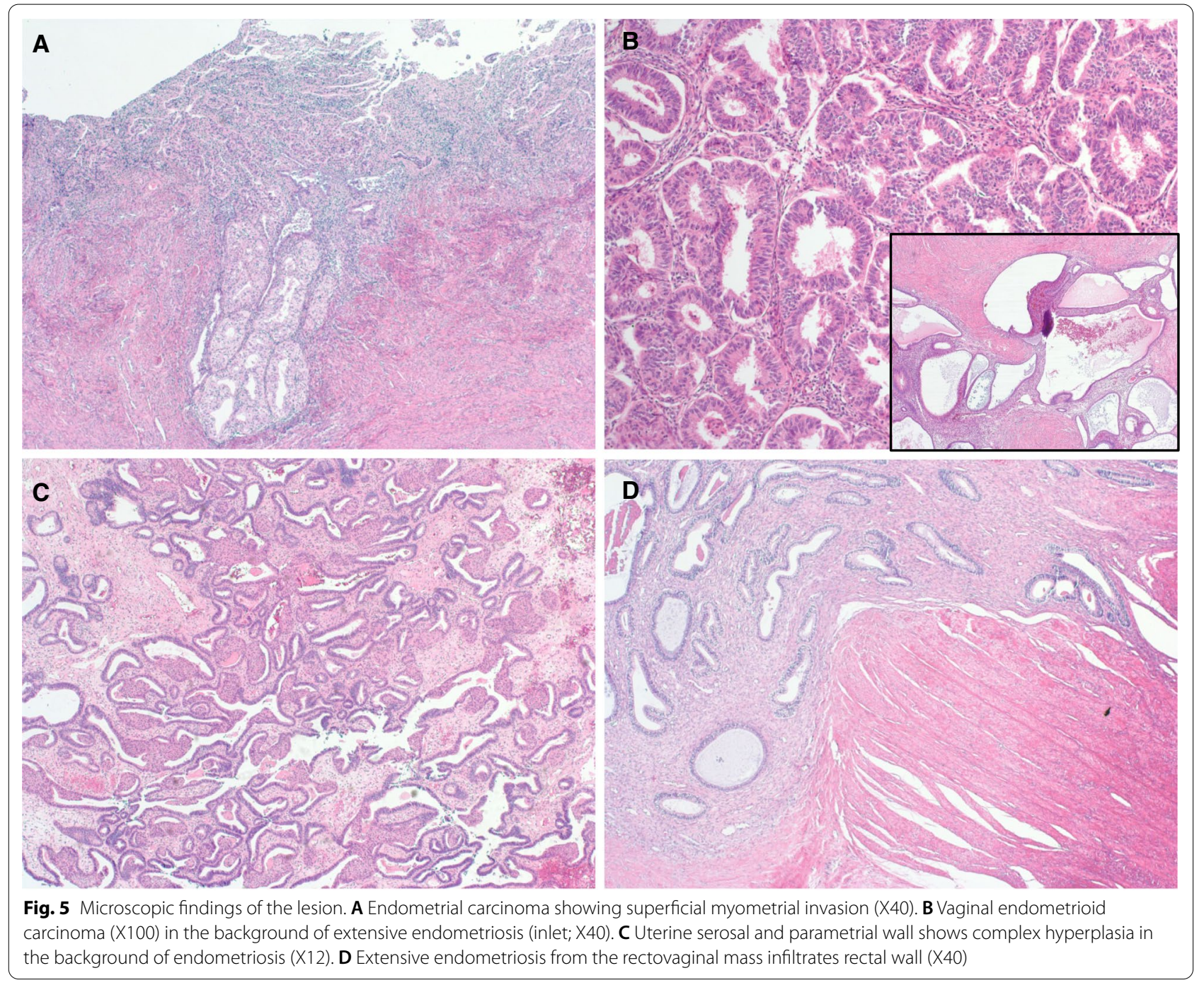

stimulates prostaglandin E2 production, which promotes tumor growth and triggers aromatase activity, resulting in a positive feedback loop in favor of continuous estrogen formation in endometriosis [22, 24].

In obese women, the peripheral conversion of steroid hormones into estrone by aromatase increases, leading to a hyperestrogenic environment. Zanetta compared 31 patients with 62 controls and found that obese women using unopposed exogenous estrogen had a significantly increased risk of developing cancer from endometriosis $(P=0.05)$ [25]. The patient had a BMI of $36.4 \mathrm{~kg} /$ $\mathrm{m}^{2}$, and obesity-related hyperestrogenism might have been responsible for the malignant transformation of endometriosis.

Endometrial cancer is a malignant epithelial tumor that forms in the endometrium. It is the most common gynecologic malignancy in the United States [26]. The risk factors for endometrial cancer include increased estrogen levels (caused by obesity, diabetes, and highfat diet), early age at menarche, nulliparity, late age at menopause, older age, and tamoxifen use [27-30]. Endometriosis is related to endometrial cancer, reflecting overlapping risk factors, such as endogenous or exogenous hyperestrogenism and ovulatory dysfunction $[9$, 10]. In a recent meta-analysis, endometrial cancer risk is $40 \%$ higher in women with endometriosis [31].

This patient was diagnosed as stage I endometriosisassociated vaginal cancer and synchronous stage IA1 endometrial cancer. The patient required the comprehensive treatment because of the combined vaginal cancer on endometriosis and endometrial cancer. Given the limited experience with endometriosis-associated vaginal carcinoma, the optimal management remains poorly established. Surgical excision of malignant lesions is employed uniformly in most patients. However, the need and composition of adjuvant therapy are 
not uniform and depend on patient and tumor characteristics [16]. For patients with epithelial tumors, adjuvant treatment is less frequently employed. The patient had residual endometriosis involving her vagina and rectum (resection margin with endometriosis). Medical treatment after the operation of rectovaginal endometriosis is important [32]. In the case, the progestational agent was treated to suppress any propagation of residual endometriosis.

This case demonstrated a multistep transformation from endometriosis to complex hyperplasia to endometrioid carcinoma. The progression was individualized between implantation sites and even in the same organ. Once surgery is indicated, complete excision of endometriosis lesions is needed because the remnant lesion might include the concealed malignancy.

\section{Abbreviations}

BMI: Body Mass Index; FIGO: International Federation of Gynecologic Oncology.

\section{Acknowledgements \\ Not applicable.}

\section{Authors' contributions}

JHK: Manuscript writing. SHS: Manuscript conception and finalizing, responsible Surgeon. GK: Manuscript editing, responsible pathologist. KAK: Responsible Imager. WRK: Responsible Surgeon. All Authors read and approved the manuscript.

\section{Funding}

No funding or financial support has been allocated for this project.

\section{Availability of data and materials}

The datasets used in the current study are available from the corresponding author on reasonable request.

\section{Declarations}

\section{Ethics approval and consent to participate}

This study was approved by the Institutional Review Board of CHA Bundang Medical Center, CHA University School of Medicine (IRB No. 2020-05-009).

\section{Consent for publication}

Written consent from the patient for publication was obtained.

\section{Competing interests}

All authors have no potential conflicts of interest to disclose.

\section{Author details}

'Department of Fertility Center, CHA Bundang Medical Center, CHA University School of Medicine, Seongnam, South Korea. ${ }^{2}$ Department of Comprehensive Gynecologic Cancer Center, CHA Bundang Medical Center, CHA University School of Medicine, Seongnam-si, Gyeonggi-do 13496, South Korea. ${ }^{3}$ Department of Pathology, CHA Bundang Medical Center, CHA University School of Medicine, Seongnam, South Korea. ${ }^{4}$ Department of Radiology, CHA Bundang Medical Center, CHA University School of Medicine, Seongnam, South Korea. ${ }^{5}$ Department of Surgery, CHA Bundang Medical Center, CHA University School of Medicine, Seongnam, South Korea.

Received: 3 January 2021 Accepted: 21 June 2021 Published online: 12 July 2021

\section{References}

1. Vercellini P, Vigano P, Somigliana E, Fedele L. Endometriosis: pathogenesis and treatment. Nat Rev Endocrinol. 2014:10:261-75.

2. Parasar P, Ozcan P, Terry KL. Endometriosis: epidemiology, diagnosis and clinical management. Curr Obstet Gynecol Rep. 2017;6:34-41.

3. Donarini P, Ciravolo G, Rampinelli F, Odicino F, Ferrari FG, Sartori E. Parametrial endometriosis with ureteral involvement: a case report of a conservative approach without ureteral resection. J Endometr Pelvic Pain Disord. 2018;10:222-3.

4. Lakhwani P, Kumar K. vaginal endometriosis: an enigma for clinicians. Indian J Gynecol Oncol. 2019;17:34.

5. Nelson P. Endometriosis presenting as a vaginal mass. BMJ Case Rep. 2018:2018:bcr-2017-222431.

6. Heaps JM, Nieberg RK, Berek JS. Malignant neoplasms arising in endometriosis. Obstet Gynecol. 1990;75:1023-8.

7. Ferrari F, Valenti G, Forte S, Ardighieri L, Iraci Sareri M, Barra F, et al. Clear cell degeneration associated with endometriosis of abdominal wall after cesarean section: a case report and systematic review of literature. J Obstet Gynaecol Res.

8. Masand RP, Euscher ED, Deavers MT, Malpica A. Endometrioid stromal sarcoma: a clinicopathologic study of 63 cases. Am J Surg Pathol. 2013:37:1635-47.

9. Burghaus S, Haberle L, Schrauder MG, Heusinger K, Thiel FC, Hein A, et al. Endometriosis as a risk factor for ovarian or endometrial cancer-results of a hospital-based case-control study. BMC Cancer. 2015;15:751.

10. Wilbur MA, Shih IM, Segars JH, Fader AN. Cancer implications for patients with endometriosis. Semin Reprod Med. 2017;35:110-6.

11. Yu H-C, Lin C-Y, Chang W-C, Shen B-J, Chang W-P, Chuang C-M. Increased association between endometriosis and endometrial cancer: a nationwide population-based retrospective cohort study. Int J Gynecol Cancer. 2015;25:447-52.

12. Ferrari F, Forte S, Ardighieri L, Bonetti E, Fernando B, Sartori E, et al. Multivariate analysis of prognostic factors in primary squamous cell vulvar cancer: the role of perineural invasion in recurrence and survival. Eur J Surg Oncol. 2019:45:2115-9.

13. Wu X, Matanoski G, Chen VW, Saraiya M, Coughlin SS, King JB, et al. Descriptive epidemiology of vaginal cancer incidence and survival by race, ethnicity, and age in the United States. Cancer. 2008;113:2873-82.

14. Creasman WT, Phillips JL, Menck HR. The National Cancer Data Base report on cancer of the vagina. Cancer. 1998;83:1033-40.

15. Staats PN, Clement PB, Young RH. Primary endometrioid adenocarcinoma of the vagina: a clinicopathologic study of 18 cases. Am J Surg Pathol. 2007;31:1490-501.

16. Cozzolino M, Nasioudis D, Sisti G, Coccia ME. Malignant transformation of vaginal endometriosis - a review of literature. Gynecol Obstet Investig. 2017:82:105-12.

17. Sampson JA. Endometrial carcinoma of the ovary, arising in endometrial tissue in that organ. Arch Surg. 1925;10:1-72.

18. Grandi G, Toss A, Cortesi L, Botticelli L, Volpe A, Cagnacci A. The association between endometriomas and ovarian cancer: preventive effect of inhibiting ovulation and menstruation during reproductive life. Biomed Res Int. 2015;2015:751571.

19. Czernobilsky B, Morris WJ. A histologic study of ovarian endometriosis with emphasis on hyperplastic and atypical changes. Obstet Gynecol. 1979:53:318-23.

20. PB C. Diseases of the peritoneum. In: Kurman RJ, ed. Blaustein's pathology of the female genital tract. New York: Springer; 2002.

21. Worley MJ, Welch WR, Berkowitz RS, Ng SW. Endometriosis-associated ovarian cancer: a review of pathogenesis. Int J Mol Sci. 2013;14:5367-79.

22. Zeitoun KM, Bulun SE. Aromatase: a key molecule in the pathophysiology of endometriosis and a therapeutic target. Fertil Steril. 1999;72:961-9.

23. Khorram O, Taylor RN, Ryan IP, Schall TJ, Landers DV. Peritoneal fluid concentrations of the cytokine RANTES correlate with the severity of endometriosis. Am J Obstet Gynecol. 1993;169:1545-9.

24. Munksgaard PS, Blaakaer J. The association between endometriosis and ovarian cancer: a review of histological, genetic and molecular alterations. Gynecol Oncol. 2012;124:164-9.

25. Zanetta GM, Webb MJ, Li H, Keeney GL. Hyperestrogenism: a relevant risk factor for the development of cancer from endometriosis. Gynecol Oncol. 2000;79:18-22. 
26. Koh WJ, Abu-Rustum NR, Bean S, Bradley K, Campos SM, Cho KR, et al. Uterine neoplasms, Version 1.2018, NCCN Clinical practice guidelines in oncology. J Natl Compr Canc Netw. 2018;16:170-99.

27. Dinkelspiel HE, Wright JD, Lewin SN, Herzog TJ. Contemporary clinical management of endometrial cancer. Obstet Gynecol Int. 2013;2013:583891.

28. Kitchener HC, Trimble EL. Endometrial cancer state of the science meeting. Int J Gynecol Cancer. 2009;19:134-40.

29. Obermair A, Youlden DR, Young JP, Lindor NM, Baron JA, Newcomb P, et al. Risk of endometrial cancer for women diagnosed with HNPCCrelated colorectal carcinoma. Int J Cancer. 2010;127:2678-84.

30. Van den Bosch T, Coosemans A, Morina M, Timmerman D, Amant F. Screening for uterine tumours. Best Pract Res Clin Obstet Gynaecol. 2012;26:257-66.
31. Gandini S, Lazzeroni M, Peccatori FA, Bendinelli B, Saieva C, Palli D, et al. The risk of extra-ovarian malignancies among women with endometriosis: a systematic literature review and meta-analysis. Crit Rev Oncol Hematol. 2019;134:72-81

32. Vercellini P, Buggio L, Somigliana E. Role of medical therapy in the management of deep rectovaginal endometriosis. Fertil Steril. 2017;108:913-30.

\section{Publisher's Note}

Springer Nature remains neutral with regard to jurisdictional claims in published maps and institutional affiliations.
Ready to submit your research? Choose BMC and benefit from:

- fast, convenient online submission

- thorough peer review by experienced researchers in your field

- rapid publication on acceptance

- support for research data, including large and complex data types

- gold Open Access which fosters wider collaboration and increased citations

- maximum visibility for your research: over $100 \mathrm{M}$ website views per year

At BMC, research is always in progress.

Learn more biomedcentral.com/submissions 